\title{
INFRARED ABSORPTION OF NINETEEN HYDROCARBONS, INCLUDING TEN OF HIGH MOLECULAR WEIGHT ${ }^{1}$
}

\author{
By Frank W. Rose, Jr. ${ }^{2}$
}

\section{ABSTRACT}

The absorption spectra of 9 hydrocarbons of low molecular weight $\left(\mathrm{C}_{8}\right.$ to $\left.\mathrm{C}_{10}\right)$ and of 10 hydrocarbons of high molecular weight $\left(\mathrm{C}_{24}\right.$ to $\left.\mathrm{C}_{32}\right)$ have been recorded in the near infrared from 5400 to $8900 \mathrm{~cm}^{-1}(1.82$ to $1.12 \mu)$ with a recording infrared-glass spectrograph. Molal absorptive indices have been calculated and plotted against wave numbers. Qualitative correlations of the differences in the various spectral characteristics of certain structural types have been noted and some limitations on such interpretations indicated.

It appears that these data can now be correlated quantitatively with respect to structural units of hydrocarbon molecules. The results of such a study on the infrared absorption spectra of 54 hydrocarbons follow in a subsequent report.

\section{CONTENTS}

Page

I. Introduction $\ldots \ldots \ldots$

II. Experimental procedure

III. Source and nature of the hydrocarbons

IV. Results .............. 146

1. Hydrocarbons of low molecular weight

(a) Absorption from 7900 to $8900 \mathrm{~cm}^{-1} \ldots \ldots \ldots \ldots 147$

(b) Absorption from 6400 to $7400 \mathrm{~cm}^{-1} \ldots 148$

(c) Absorption from 5400 to $6400 \mathrm{~cm}^{-1} \ldots 149$

2. Hydrocarbons of high molecular weight

(a) Absorption from 7900 to $8900 \mathrm{~cm}^{-1} \ldots$

(b) Absorption from 6400 to $7400 \mathrm{~cm}^{-1} \ldots \ldots \ldots$

(c) Absorption from 5400 to $6400 \mathrm{~cm}^{-1} \ldots 155$

V. Discussion of results _...

VI. References

\section{INTRODUCTION}

The association of the infrared absorption spectra of hydrocarbons with their structural types was substantiated in a previous report on 35 hydrocarbons of low molecular weight [1]. ${ }^{3}$ The development of the theory may be found in the literature there cited.

In order to make the results, in conjunction with certain other properties, of greater value in the problem of identifying the hydrocarbon constituents of petroleum, data on more compounds of different types, and especially those of higher molecular weight, were needed. The present report gives new experimental data for 19 hydrocarbons, 9 of low and 10 of high molecular weight, together with additional correlations of their spectra with respect to structural groups.

1 Financial assistance has been received from the research fund of the American Petroleum Institute. This work is part of Project 6, The Separation, Identification, and Determination of the Constituents of Petroleum.

\& Research Associate at the National Bureau of Standards, representing the American Petroleuin Institute.

3 Figures in brackets here and throughout the text refer to the references at the end of the paper. 


\section{EXPERIMENTAL PROCEDURE}

The spectrograph employed in the present, as well as the previous [1] investigation, was described in its mechanical details by Brackett and Liddel [2]. The intensity of transmitted radiation is measured by a thermocouple and automatically recorded on a photographic plate as deflections of a sensitive galvanometer. The manipulation of the apparatus and the experimental technique involved have been adequately explained in earlier papers by Wulf and Liddel $[1,3,4]$.

After applying the appropriate corrections as noted by these authors there is obtained the fraction of the incident light transmitted, $I / I_{0}$, through the solution at the various wave lengths. From these data, the molal absorptive index may be calculated,

$$
K=\frac{-\log _{10} I / I_{0}}{c d}
$$

where $I$ is the intensity of the transmitted light, $I_{0}$ the incident light, $c$ the concentration in moles per liter, and $d$ the cell depth in centimeters. The molal absorptive index, $K$, is then plotted against wave number (the wave number is $1 / \lambda$, where $\lambda$ is the wave length in centimeters).

Solutions of the hydrocarbons in purified carbon tetrachloride were utilized in all cases (since this solvent has no significant absorption in this region). The solutions, studied in a 10-cm absorption cell, had the following approximate concentrations: for the hydrocarbons of low molecular weight, 0.5 molal for the region 6400 to $8900 \mathrm{~cm}^{-1}$ and 0.1 molal for the region 5400 to $6400 \mathrm{~cm}^{-1}$; for the hydrocarbons of high molecular weight the concentrations for these regions were 0.1 and 0.02 molal, respectively.

\section{SOURCE AND NATURE OF THE HYDROCARBONS}

The nine hydrocarbons of low molecular weight included in this report are:

2-Methylnonane.
3-Methylnonane.
4-Methylnonane.
5-Methylnonane.
n-Propylbenzene.

Isopropylbenzene.

3, 5, 5-Trimethylheptane.

$3,4,5,5$-Tetramethylhexane.

Ethylcyclohexane.

The samples of 2-methylnonane, 3-methylnonane, 4-methylnonane, and 5-methylnonane were obtained from Dr. G. Calingaert of the Ethyl Gasoline Corporation, who has already described their synthesis and properties [5]. The samples of 3, 5, 5-trimethylheptane and 3, 4, 5, 5-tetramethylhexane were obtained from Prof. N. L. Drake of Maryland University, and their synthesis and properties will be described in a forthcoming publication [6]. The sample of isopropylbenzene was prepared by careful fractionation, at $215 \mathrm{~mm}$ $\mathrm{Hg}$ pressure, in a distilling column packed with $240 \mathrm{~cm}$ of locket-chain from crude synthetic stock obtained from Prof. W. B. Holton of American University [7]. The sample of $n$-propylbenzene was purified by distillation (in the same manner as the isopropylbenzene) from crude synthetic stock obtained from Prof. E. E. Reid of the Johns Hopkins University [8]. The sample of ethylcyclohexane was syn- 
thesized by Rose and White, who described its properties [9]. The properties of the isopropyl- and $n$-propylbenzene will be described in forthcoming publications [17]. Figures are not given for the purities of the samples used, although, with the exception of 3,5,5-trimethylheptane and 3,4,5,5-tetramethylhexane, the purity of all the samples was considered more than adequate for this work (95\%). Furthermore the impurities are probably similar hydrocarbons whose effect is relatively small. These samples may, of course, be identified by their physical properties found in the references cited. Each of the exceptions noted may contain substantial amounts of the other.

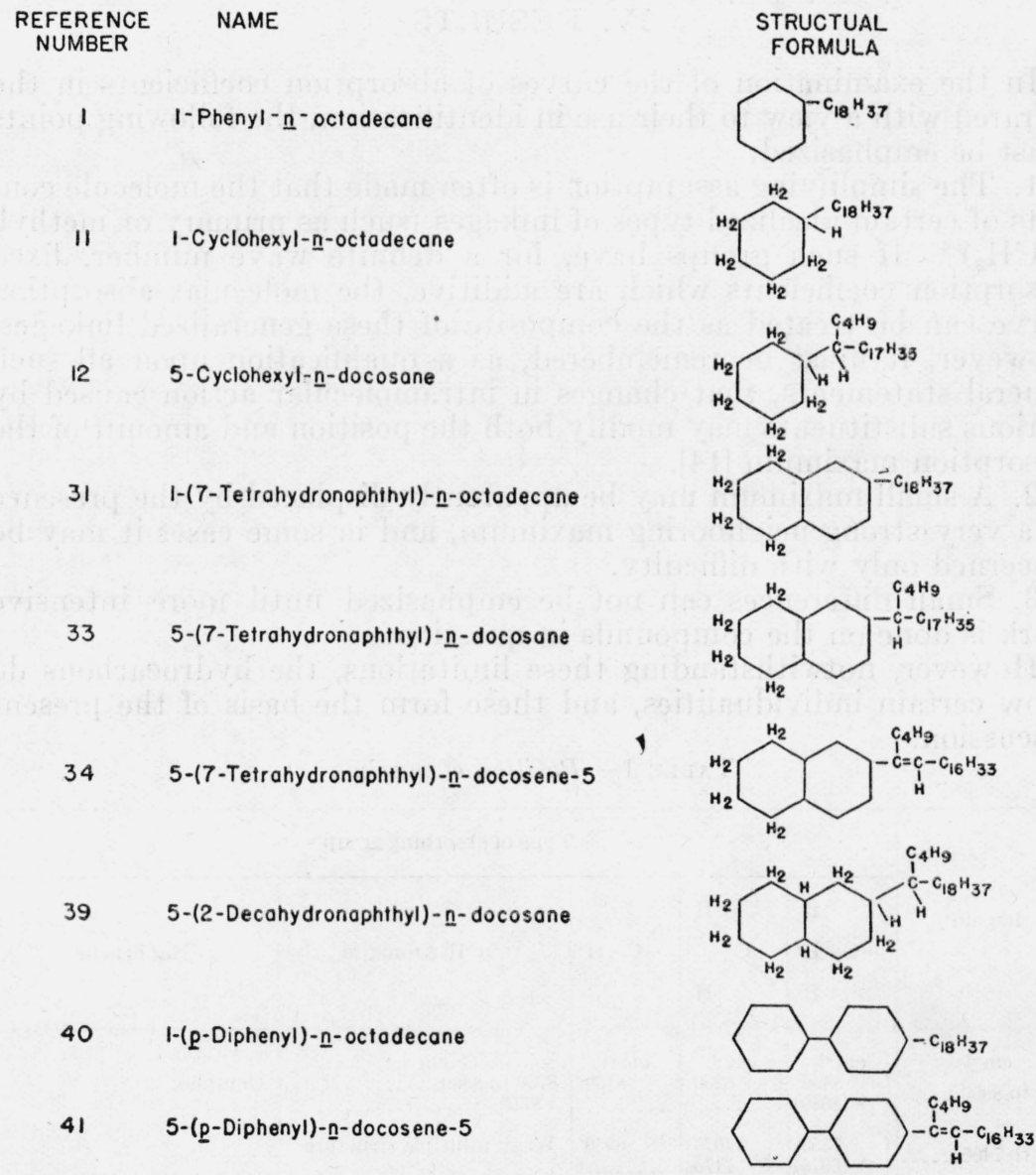

Figure 1.-Structural formulas of high molecular weight hydrocarbons.

The reference numbers in this figure are the same as those used in Mikeska's paper [10].

The hydrocarbons of high molecular weight whose names and formulas are given in figure 1 were kindly lent for this and other work by Dr. L. A. Mikeska of the Standard Oil Development Co., who synthesized these compounds and determined a number of their properties [10]. Mikeska reported that "No attempt has been made to establish the relative position of the substituents in the benzene derivatives nor 
the exact location of the side chain or chains in the naphthalene derivatives." It is likely that, because of the similarity in the method of synthesis, the position is identical for all derivatives of the same aromatic nucleus. Furthermore, such a distinction lies somewhat beyond the scope of the present investigation.

The n-nonacosane $\left(\mathrm{C}_{29} \mathrm{H}_{60}\right)$ was a sample of high purity, prepared by Dr. K. S. Markley, Bureau of Plant Industry, U. S. Department of Agriculture, from the cuticle of Rome Beauty apples. The physical constants of this compound have been described [11], [12]. A determination of the carbon-hydrogen ratio in this laboratory gave further proof of its purity [13].

\section{RESULTS}

In the examination of the curves of absorption coefficients in the infrared with a view to their use in identification, the following points must be emphasized:

1. The simplifying assumption is often made that the molecule consists of certain idealized types of linkages (such as primary or methyl, $\left.-\mathrm{CH}_{3}\right)^{4}$ If such groups have, for a definite wave number, fixed absorption coefficients which are additive, the molecular absorption curve can be treated as the composite of these generalized linkages. However, it must be remembered, as a qualification upon all such general statements, that changes in intramolecular action caused by various substituents may modify both the position and amount of the absorption maximum [14].

2. A small maximum may be apparently displaced by the presence of a very strong neighboring maximum, and in some cases it may be discerned only with difficulty.

3. Small differences can not be emphasized until more intensive work is done on the compounds in question.

However, notwithstanding these limitations, the hydrocarbons do show certain individualities, and these form the basis of the present discussion.

TABLE 1.-Position of maxima

\begin{tabular}{|c|c|c|c|c|c|}
\hline \multirow[b]{2}{*}{ Region } & \multicolumn{5}{|c|}{ Type of absorbing group a } \\
\hline & & & & $>\mathrm{CH}$ Aromatic & Naphthene \\
\hline $\begin{array}{c}\mathrm{cm}^{-1} \\
7900 \text { to } 8900\end{array}$ & $\left\{\begin{array}{c}\mathrm{cm}^{-1} \\
8400 \\
b(8680)\end{array}\right.$ & $\mathrm{cm}^{-1} 8250$ & $\mathrm{~cm}^{-1} 8150$ & $\begin{array}{l}\mathrm{cm}^{-1} \\
8700 \text { to } 8800 \\
\text { e } 8750\end{array}$ & Complex. \\
\hline 6400 to 7400 & $\left\{\begin{array}{r}7350 \\
\text { b }(6975)\end{array}\right.$ & $\begin{array}{r}\text { d } 7075 \\
7175\end{array}$ & 6950 & Weak multiple structure. - & \\
\hline 5400 to $6400 \ldots$ & $\left\{\begin{array}{l}5860 \\
5900\end{array}\right.$ & $\begin{array}{l}5670 \\
5790\end{array}$ & & f About 5900 & Similar to $n$-aliphatics. \\
\hline
\end{tabular}

a See footnote 4, p. 146.

b Weak.

- Median of absorption shifts to lower frequencies with increasing length of chain.

d Affected by substitution.

- Constant in position and magnitude for monosubstituted derivatives. With polysubstitution varies $\pm 100 \mathrm{~cm}^{-1}$.

${ }_{1}$ Three peaks appear near this point. Substitution radically changes the relative intensities.

- Hereafter an incomplete valence bond indicates the attachment to the remainder of the molecule through another $\mathrm{C}$ atom. 
In table 1 are given the generalizations of the previous work [1], together with two additions from the present investigation. The wave numbers given for any absorption peak may vary over a range of \pm 50 wave numbers, depending on the nature of the remainder of the molecule. This table is given merely as an aid in interpreting the diagrams, and the values given should not be construed as exact numerical data.

\section{HYDROCARBONS OF LOW MOLECULAR WEIGHT}

(a) ABSORPTION FROM 7900 TO $8900 \mathrm{~cm}^{-1}$

The $n$-propyl- and isopropylbenzenes (fig. 2) reveal maxima in the absorption curves in accord with those of simpler compounds. Briefly the peaks and associated groups are: $8750 \mathrm{~cm}^{-1}$, aromatic; $8400 \mathrm{~cm}^{-1}$, primary aliphatic $\left(-\mathrm{CH}_{3}\right) ; 8250 \mathrm{~cm}^{-1}$, secondary aliphatic $\left(>\mathrm{CH}_{2}\right)$; and $8150 \mathrm{~cm}^{-1}$, tertiary aliphatic linkages $(\rightarrow \mathrm{CH})$. In contrast with the variations shown by polysubstituted phenyl derivatives, the mono-

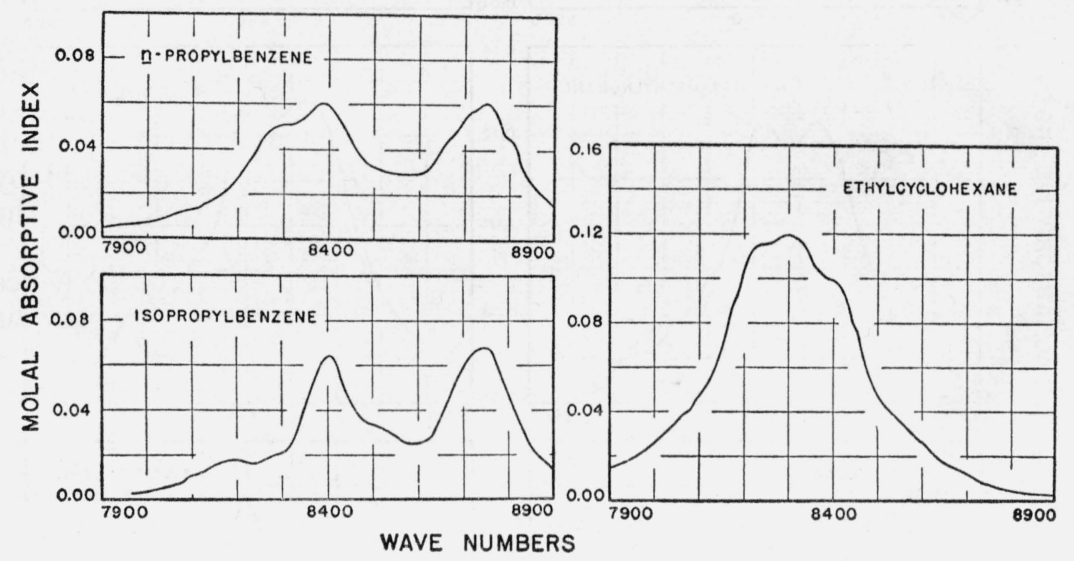

FIGURE 2.

substituted derivatives have maxima at $8750 \mathrm{~cm}^{-1}$ fairly constant both as to magnitude and position of the peak. The absorption due to the aliphatic portions of the molecules is consistent with the conclusions previously drawn [1].

The curves of ethylcyclohexane (fig. 2) are quite similar to those previously recorded for cyclohexane and methylcyclohexane [1].

The curves of the methylnonanes (fig. 3) show little variation in form but do not have the same values for the absorptive index at their maxima. These maxima show no significant displacement in frequency with change in the position of the methyl group. In the 4methylnonane, the absorption due to the methyl groups (at $8400 \mathrm{~cm}^{-1}$ and $8650 \mathrm{~cm}^{-1}$ ) seems to be more intense than in the other isomers. The absorption characteristic of a single tertiary group $(\rightarrow \mathrm{CH})$ in such a large molecule is apparently not detectable, since there is no indication of a peak at $8150 \mathrm{~cm}^{-1}$. It is interesting to note that the methylnonanes (three primary $\left(-\mathrm{CH}_{3}\right)$ and six secondary groups $\left(>\mathrm{CH}_{2}\right)$, ratio $\left.1: 2\right)$ show the same relation between the maxima at 8400 and $8250 \mathrm{~cm}^{-1}$ as does $n$-hexane [1], (two primary $\left(-\mathrm{CH}_{3}\right)$ and four secondary groups $\left(>\mathrm{CH}_{2}\right)$, ratio $\left.1: 2\right)$. 
The compounds 3,4,5,5-tetramethylhexane and 3,5,5-trimethylheptane (fig. 3) are highly methylated, having six and five primary $\left(-\mathrm{CH}_{3}\right)$ groups, respectively. Both show the expected characteristic peak at $8400 \mathrm{~cm}^{-1}$, the latter having somewhat greater secondary $\left(>\mathrm{CH}_{2}\right)$ absorption at $8250 \mathrm{~cm}^{-1}$. Neither shows obvious absorption characteristics of tertiary $(\rightarrow \mathrm{CH})$ groups.
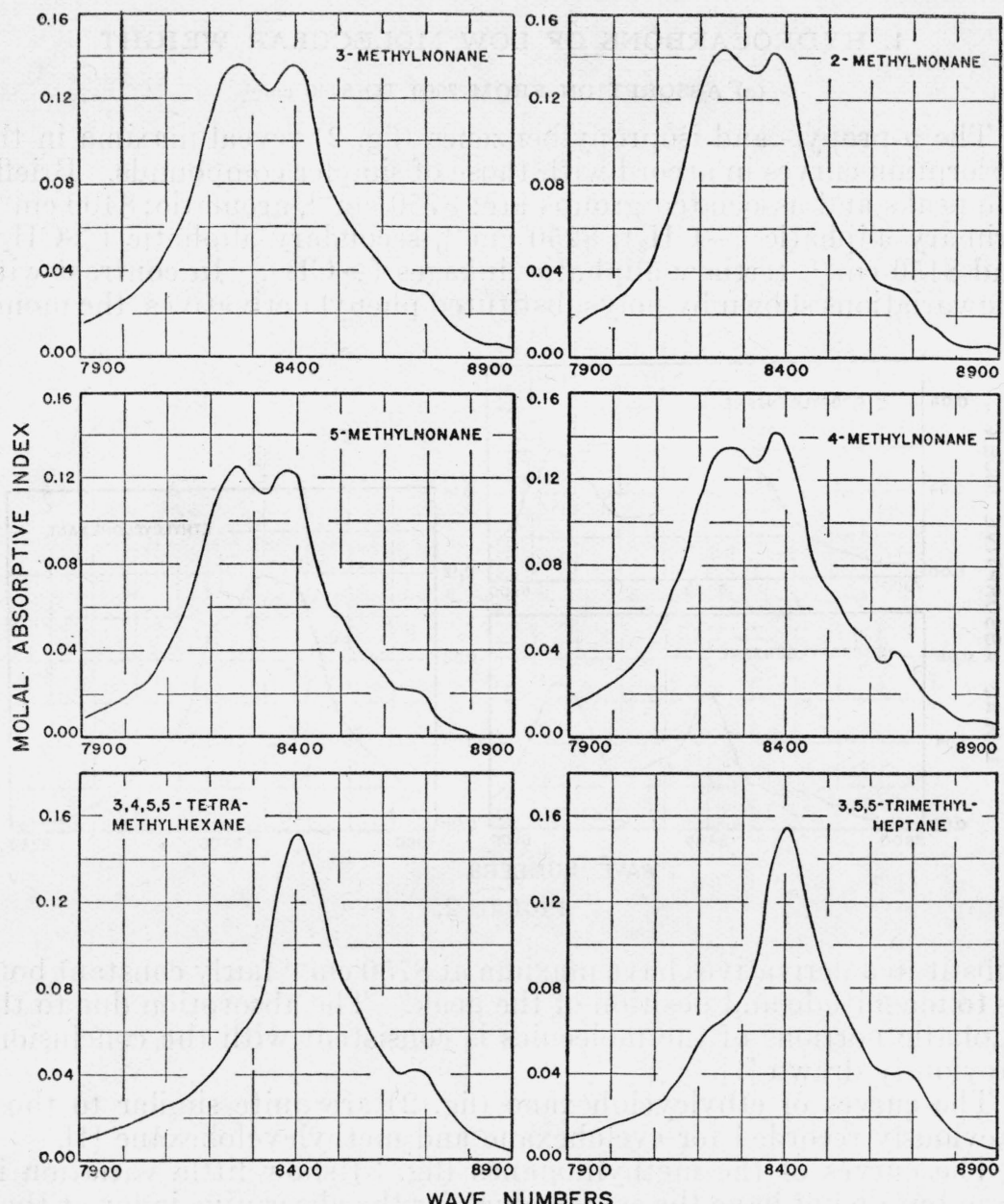

FIGURE 3.

(b) ABSORPTION FROM 6400 TO $7400 \mathrm{~cm}^{-1}$

In this region, $n$-propylbenzene and isopropylbenzene (fig. 4) show the weak multiple absorption typical of aromatic derivatives.

The ethylcyclohexane curve (fig. 4) is quite similar to those of methylcyclohexane and cyclohexane, and is similar to those of the $n$-aliphatics but less intense. 
The absorption curves of the methylnonanes (fig. 5) are indistinguishable from each other in this region, which indicates that a change in the position of the methyl group on the chain causes no detectable change in the absorption curve, possibly on account of the size of the molecule. Even similar compounds of lower molecular weight previously studied show considerably smaller differences in this region than in the region 7900 to $8900 \mathrm{~cm}^{-1}$.

The absorption curves of 3,4,5,5-tetramethylhexane and 3,5,5trimethylheptane (fig. 5) have a complicated structure which has not yet been separated into the different components. Both curves resemble those of highly methylated structures (2,2,3-trimethylbutane and 2,2,4-trimethylpentane) in the earlier study [1].

(c) ABSORPTION FROM 5400 TO $6400 \mathrm{~cm}^{-1}$

The presence of many maxima in close proximity, but which are attributed to structures quite different from one another renders this region less susceptible to analysis. There may be distinguished

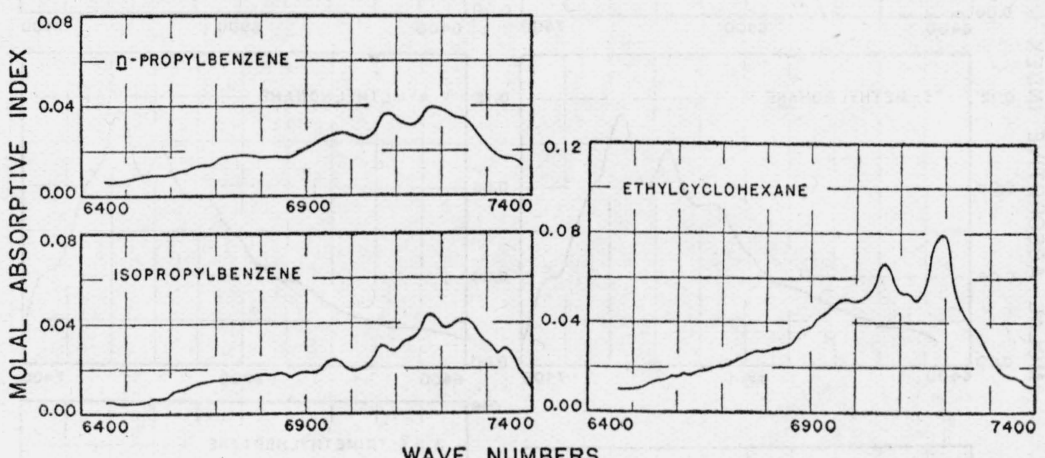

FIgURE 4.

absorption caused by secondary $\left(>\mathrm{CH}_{2}\right)$ linkages at $5700 \mathrm{~cm}^{-1}$ in the curve for $n$-propylbenzene (fig. 6). While the maximum at 5950 $\mathrm{cm}^{-1}$ is present and has nearly the same intensity in both $n$-propyland isopropylbenzene (fig. 6), the latter shows a higher peak at 5910 $\mathrm{cm}^{-1}$, which is caused by the presence of more methyl groups. The remark made above concerning monosubstituted phenyl derivatives; i. e., that the maximum is more constant both as to magnitude and position than for the polysubstituted derivatives, can be repeated here, with the additional comment that less complexity is observed (in sharp contrast with hemimellitene, pseudocumene, and mesitylene, as previously reported).

Ethylcyclohexane (fig. 6) exhibits the characteristics of secondary aliphatic absorption in this region and little else.

As in the other regions, the absorption curves of the methylnonanes (fig. 7) are again alike in shape. Variation in intensity occurs, and it may be remarked that almost the same order is followed here as was shown in the absorption from 7900 to $8900 \mathrm{~cm}^{-1}$. In general, the curves are typical of an aliphatic hydrocarbon containing a small number of methyl groups. 
The 3,4,5,5-tetramethylhexane and the 3,5,5-trimethylheptane (fig. 7) have maxima indicative of methyl groups.

\section{HYDROCARBONS OF HIGH MOLECULAR WEIGHT}

(a) ABSORPTION FROM 7900 TO $8900 \mathrm{~cm}^{-1}$

The absorption curve of $n$-nonacosane $\left(\mathrm{C}_{29} \mathrm{H}_{60}\right)$ may be considered an excellent example of the absorption resulting from the presence of a

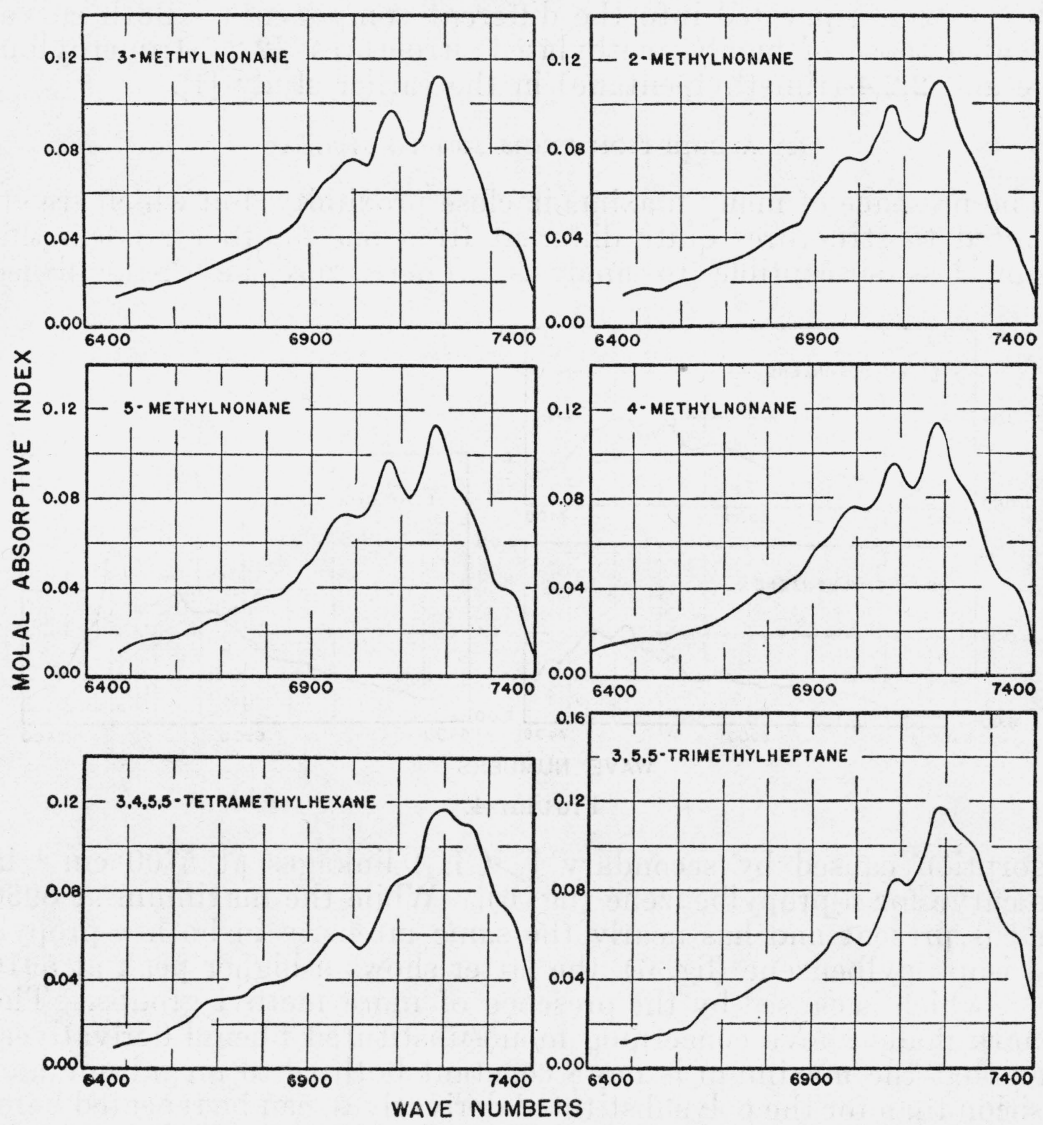

FIGURE 5.

number of average $>\mathrm{CH}_{2}$ groups. In the molecule $\mathrm{R}-\left(\mathrm{CH}_{2}\right)_{n}-\mathrm{R}^{\prime}$, the absorption due to $>\mathrm{CH}_{2}$ is modified where $\mathrm{R}$ and $\mathrm{R}^{\prime}$ are groups containing a small number of carbon atoms (methyl to propyl). In $n$-nonacosane (fig. 8 ) such disturbances are proportionally small. It may be observed that the secondary $\left(>\mathrm{CH}_{2}\right)$ group causes a single peak in this region (at $8250 \mathrm{~cm}^{-1}$ ) which nicely confirms the earlier statement of Brackett [15]. Inasmuch as no maximum in the absorption curve of this compound occurs at $8680 \mathrm{~cm}^{-1}$ the peak found at this point in other compounds having a larger proportion of methyl groups may be allocated to primary $\left(-\mathrm{CH}_{3}\right)$ absorption. It is, however, a weak absorption best observed in highly methylated struc- 
tures. Its use is minor in the detection of primary $\left(-\mathrm{CH}_{3}\right)$ groups, but is noted here to avoid possible ambiguities in the interpretation of the aromatic absorption at 8700 to $8800 \mathrm{~cm}^{-1}$.

Since the compound 1-phenyl- $n$-octadecane (fig. 9) consists of 1 phenyl, 1 primary $\left(-\mathrm{CH}_{3}\right)$, and 17 secondary $\left(>\mathrm{CH}_{2}\right)$ aliphatic groups, maxima would be expected at 8750 and $8250 \mathrm{~cm}^{-1}$ (the effect of the single primary $\left(-\mathrm{CH}_{3}\right)$ group being concealed by the preponderance of the other structures). Not only does the curve follow the anticipated shape, but the value of the absorptive index at 8750 $\mathrm{cm}^{-1}$ (aromatic absorption) almost reproduces that found for the monosubstituted phenyl groups in $n$-propyl- and isopropylbenzene, where the side chains are considerably abbreviated. This statement may be

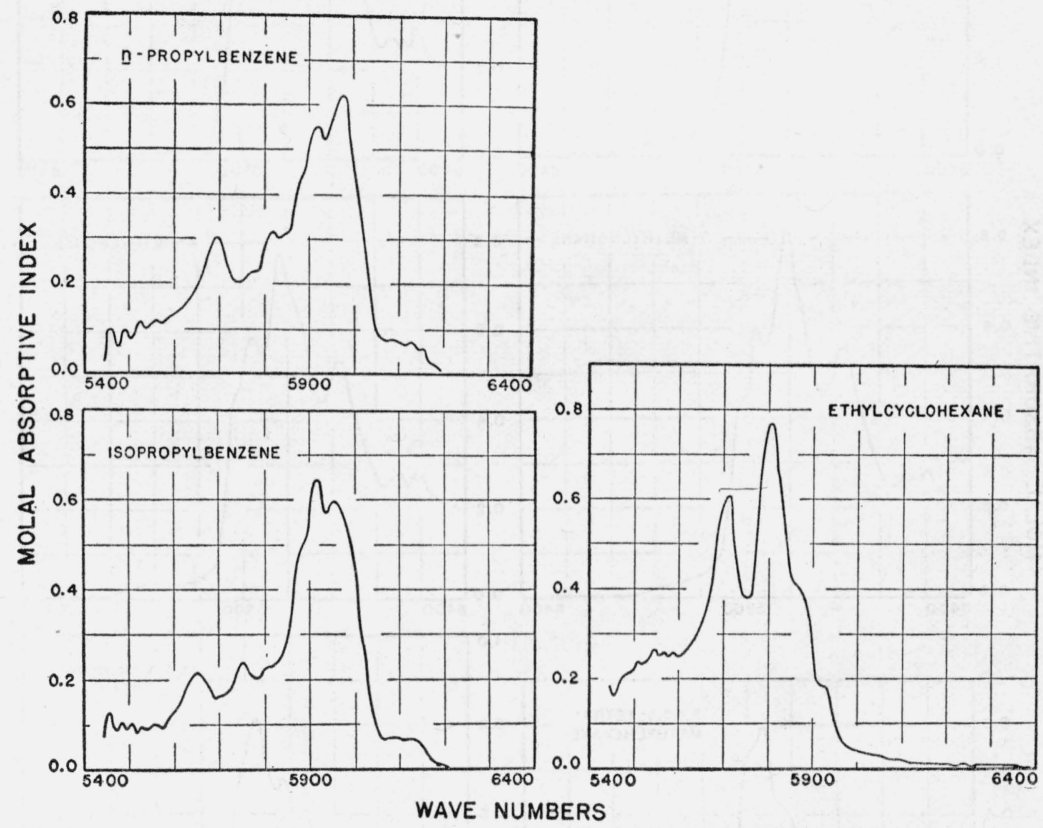

FigURE 6.

extended to include the compounds with very short side chains, such as toluene and ethylbenzene. If to this structure a phenyl group is added, as in 1-( $p$-diphenyl)- $n$-octadecane (fig. 9$)$, the difference in the absorption curves can be ascribed to the phenyl group introduced. The sole observed variation in the two curves is that in the latter the absorption is twice as intense at $8750 \mathrm{~cm}^{-1}$. The absorption curve of the compound 5 -( $p$-diphenyl)- $n$-docosene-5 (fig. 9) departs only slightly from that for 1 -( $p$-diphenyl)- $n$-octadecane. The structure includes 2 phenyl group, 18 secondary $\left(>\mathrm{CH}_{2}\right)$, and 1 primary $\left(-\mathrm{CH}_{3}\right)$ linkages as well as 1 ethylenic bond. Although this and the previous study furnish no information concerning ethylenic bonds, the effect of unsaturation may be evaluated by the data of other workers. Thus Lecomte in the most recent treatise on infrared spectra [16] states, following the work of Freyman, that aliphatic compounds containing ethylenic bonds "possess, on the whole, all the principal 
bands of the corresponding saturated hydrocarbons and a part of the secondary bands (but the latter have intensities singularly modified) and, in addition, new bands." Since only one carbon-hydrogen linkage is involved, the resulting alteration should be minor. It is, however, conceivable that the presence of this group would affect the
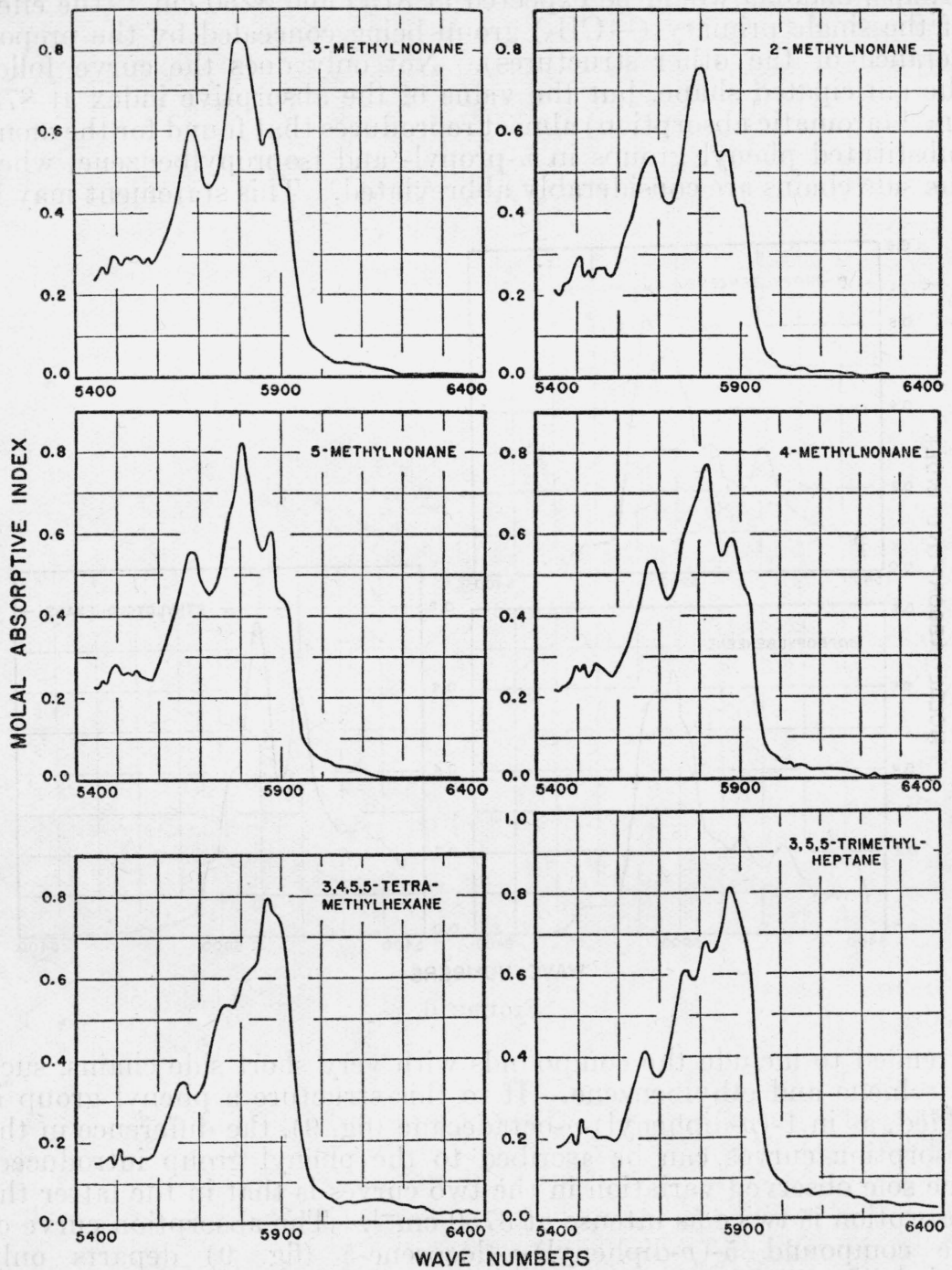

FIGURE 7

remainder of the molecule sufficiently strongly to give rise to distinctly modified absorption. Such, however, is not the case; the absorption curve is indicative only of secondary aliphatic $\left(>\mathrm{CH}_{2}\right)$ and aromatic absorption in an amount to be predicted on the basis of the saturated groups present.

The naphthenic compounds, 1-cyclohexyl-n-octadecane (fig. 9) and 5-cyclohexyl-n-docosane (fig. 9), present similar absorption 
curves, the latter logically having a greater value for the absorptive index at the maximum since the molecule possesses a larger number of secondary $\left(>\mathrm{CH}_{2}\right)$ linkages. The values of the absorptive indices for both substances are less than that for an equal number of secondary linkages $\left(>\mathrm{CH}_{2}\right)$ in a chain structure (a condition normally encountered in the saturated cyclics).

Curiously, the tetrahydronaphthyl derivatives (fig. 10) have no distinctive peak at the wave number (about $8750 \mathrm{~cm}^{-1}$ ) associated with aromatic absorption. Further, the curves are indistinguishable from those for the corresponding cyclohexyl derivatives (fig. 9), except that for the former the region 8550 to $8800 \mathrm{~cm}^{-1}$ generally shows somewhat greater absorption. In an attempt to explain this discrepancy, the probable difference in the absorption curves of $o$-diethylbenzene and tetrahydronaphthalene may be considered, the structures of which vary only in that in the latter the aliphatic chains have been joined to form a ring. The effect of ortho substitution of aliphatic groups in a phenyl group can be studied in $o$-xylene, where only a minor shift of the peak in regard to either position or magnitude is observed. If one may judge by analogy with the monosubstituted phenyl derivatives, increase in the length of the side chain causes only minor alterations. Hence, $o$-diethylbenzene would be expected to show a distinct absorption peak at 8750 $\mathrm{cm}^{-1}$. Inasmuch as the derivatives of tetrahydronaphthalene show no marked absorption at $8750 \mathrm{~cm}^{-1}$, tetrahydronaphthalene may not be expected to have a distinctive peak at this point.

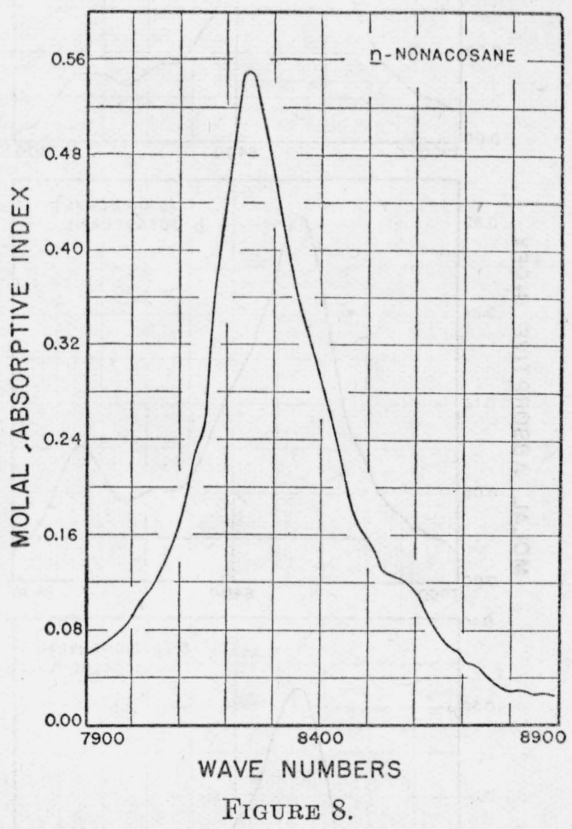
From such a conclusion, it follows that cyclization of the substituent groups of a benzene ring exercises a profound effect on the form of the absorption curve. This effect is naturally absent in 5-(2-decahydronaphthyl)- $n$-docosane (fig. 10), which consists principally of secondary linkages $\left(>\mathrm{CH}_{2}\right)$. Both the tetrahydro- and decahydronaphthyl derivatives have the same value of the absorptive index at $8250 \mathrm{~cm}^{-1}$ as do the aliphatic compounds having the same number of secondary groups $\left(>\mathrm{CH}_{2}\right)$, in contrast with the cyclohexyl derivatives which consistently show lower values.

\section{(b) ABSORPTION FROM 6400 TO $7400 \mathrm{~cm}^{-1}$}

The absorption curve of $n$-nonacosane (fig. 11) has the peaks assumed for secondary linkages $\left(>\mathrm{CH}_{2}\right)$ in the hydrocarbons of lower molecular weight but, because of the better separation of the peaks, now has maxima at 7065 and $7185 \mathrm{~cm}^{-1}$ (previously 7075 and $7175 \mathrm{~cm}^{-1}$ ).

The remainder of the compounds (fig, 12,13) have maxima at 7065 and $7185 \mathrm{~cm}^{-1}$. This is logical since they all consist principally of 
secondary linkages $\left(>\mathrm{CH}_{2}\right)$, with the exception of the three with aromatic rings. However, as stated above, aromatic rings have in this region a weak, multiple absorption that would manifest itself only by a minor increase in the values of the absorptive index over the entire curve. The presence of the ring might change the behavior of

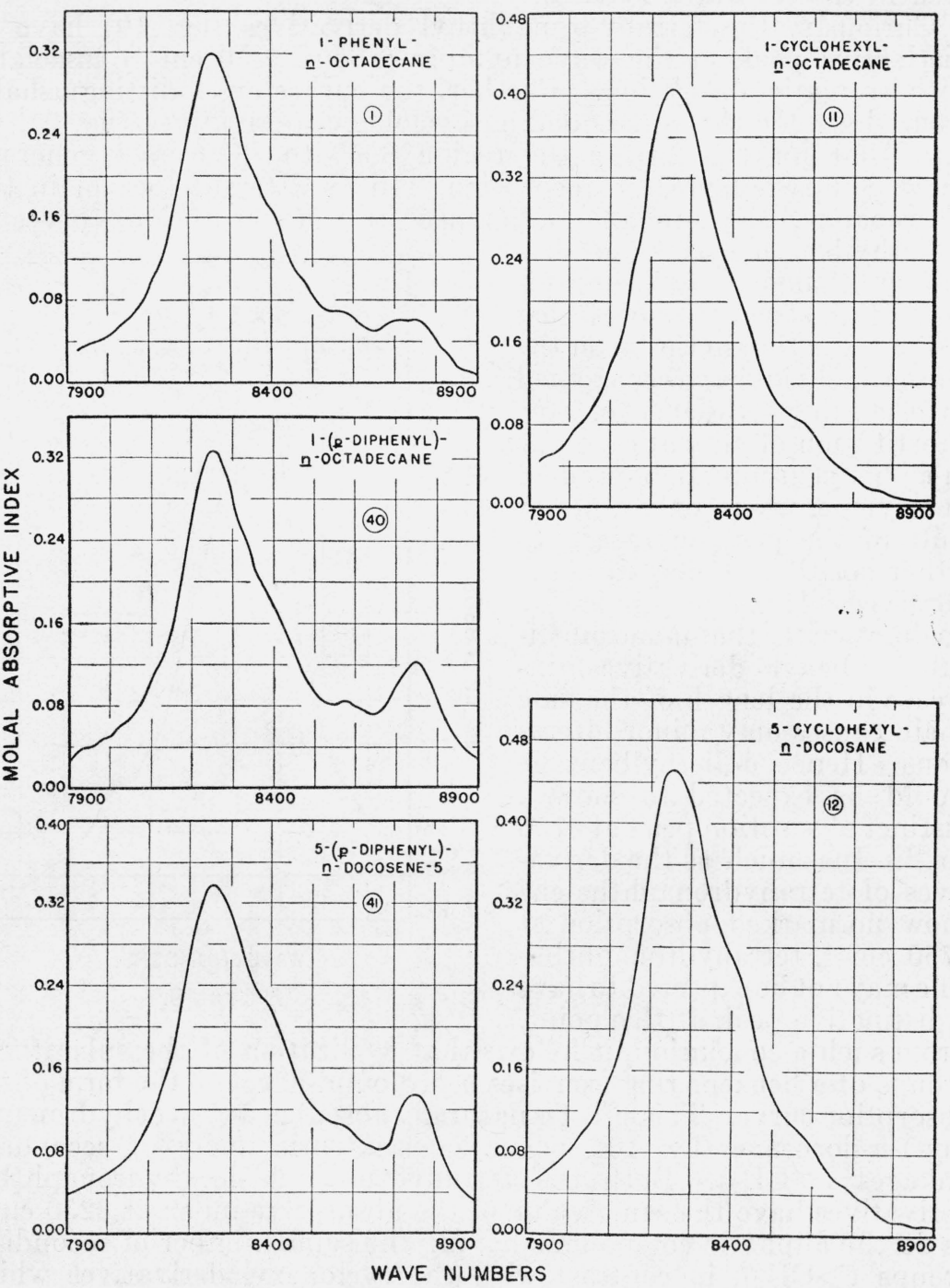

FIGURE 9.

the secondary linkages $\left(>\mathrm{CH}_{2}\right)$. Indeed, some such result is encountered, as may be seen from a consideration of the relative heights of the peaks. In 5-cyclohexyl- $n$-docosane (fig. 12) a complete reversal of the relative strengths of absorption at 7090 and $7190 \mathrm{~cm}^{-1}$ occurs. To a lesser extent, similar anomalies are evident in the majority of the compounds. Intensification and depressions of both maxima occur, although the peak at $7190 \mathrm{~cm}^{-1}$ is more often strongly affected. Any 
attempt to follow the effect of a single structural variable results only in confusion, hence no correlation of the shape or magnitude of the curve with structure has been made.

\section{(c) ABSORPTION FROM 5400 TO $6400 \mathrm{~cm}^{-1}$}

The absorption curve for $n$-nonacosane (fig. 11) substantiates the prior assignment of the maxima at 5670 and 5790 to secondary linkages $\left(>\mathrm{CH}_{2}\right)$.

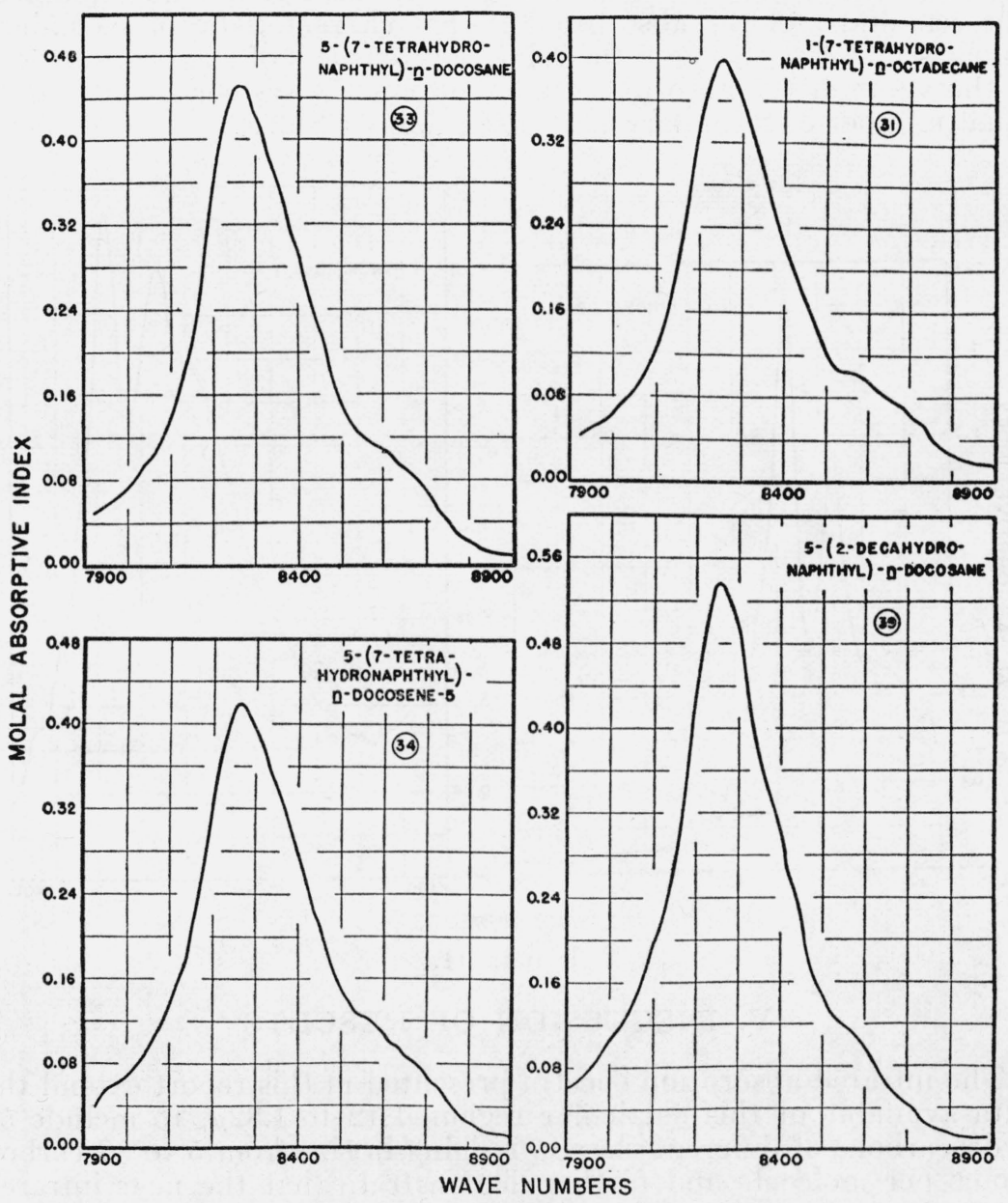

FigURE 10.

The compounds, 1 -phenyl- $n$-octadecane, 1-( $p$-diphenyl)- $n$-octadecane, and 5 ( $p$-diphenyl)- $n$-docosene-5 (fig. 14), all have maxima at or near $5990 \mathrm{~cm}^{-1}$. All the structures contain aromatic rings in addition to the secondary linkages $\left(>\mathrm{CH}_{2}\right)$. The first and second compounds vary only in the number of rings and their curves vary only in the maxima at $5990 \mathrm{~cm}^{-1}$. Hence absorption at this point may be attributed to the phenyl group. The third compound has additional absorption at $5900 \mathrm{~cm}^{-1}$ which may be related to greater proportion of 
methyl groups. The remainder of the curves show normal characteristics of secondary aliphatic $\left(>\mathrm{CH}_{2}\right)$ absorption (compare with $n$-nonacosane (fig. 11)).

In agreement with the curves of the region from 7900 to $8900 \mathrm{~cm}^{-1}$, the tetrahydronaphthyl derivatives (fig. 15), though only partially hydrogenated and still apparently possessing an "aromatic" ring, do not absorb in the interval, 5900 to $6000 \mathrm{~cm}^{-1}$, significantly more than do the decahydronaphthyl and cyclohexyl derivatives which have no phenyl groups. For the present, this can not be explained. The remainder of the absorption is that characteristic of secondary linkages $\left(>\mathrm{CH}_{2}\right)$ although the relative intensities of the peaks as well as the value of the absorptive index do not always correspond to an equal number of secondary aliphatic groups $\left(>\mathrm{CH}_{2}\right)$.
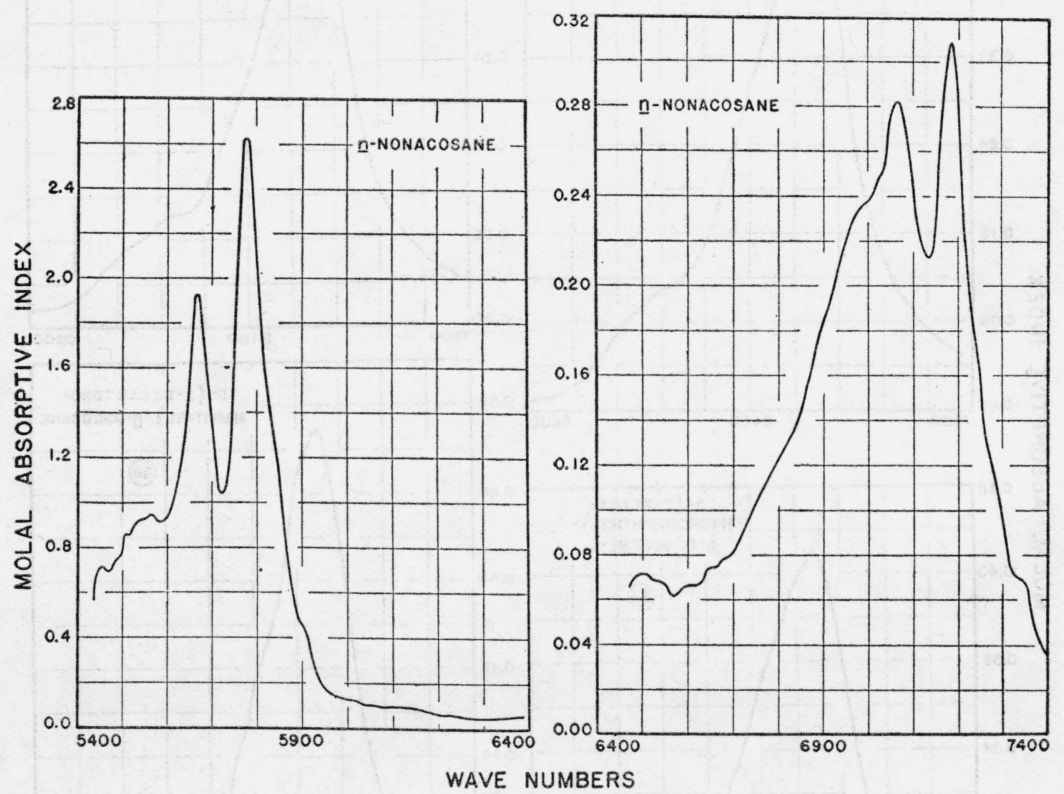

Figure 11.

\section{DISCUSSION OF RESULTS}

The infrared absorption spectra presented in this report extend the data available in this particular region, 1.12 to $1.82 \mu$, to include 54 hydrocarbons of different classes, ranging in size from 5 to 32 carbon atoms per molecule and further demonstrate that the near infrared absorption spectrum is a function of molecular structure.

Heretofore, visual comparison of the individual curves has served to give some qualitative measure of the differences in molecular structure. It appears that these data can now be correlated quantitatively with respect to the structural units $\left(-\mathrm{CH}^{3},>\mathrm{CH}^{2},>\mathrm{CH}\right.$, and aromatic of hydrocarbon molecules. The results of a mathematical analysis of the near infrared absorption spectra of these 54 hydrocarbons follow in a subsequent report. 


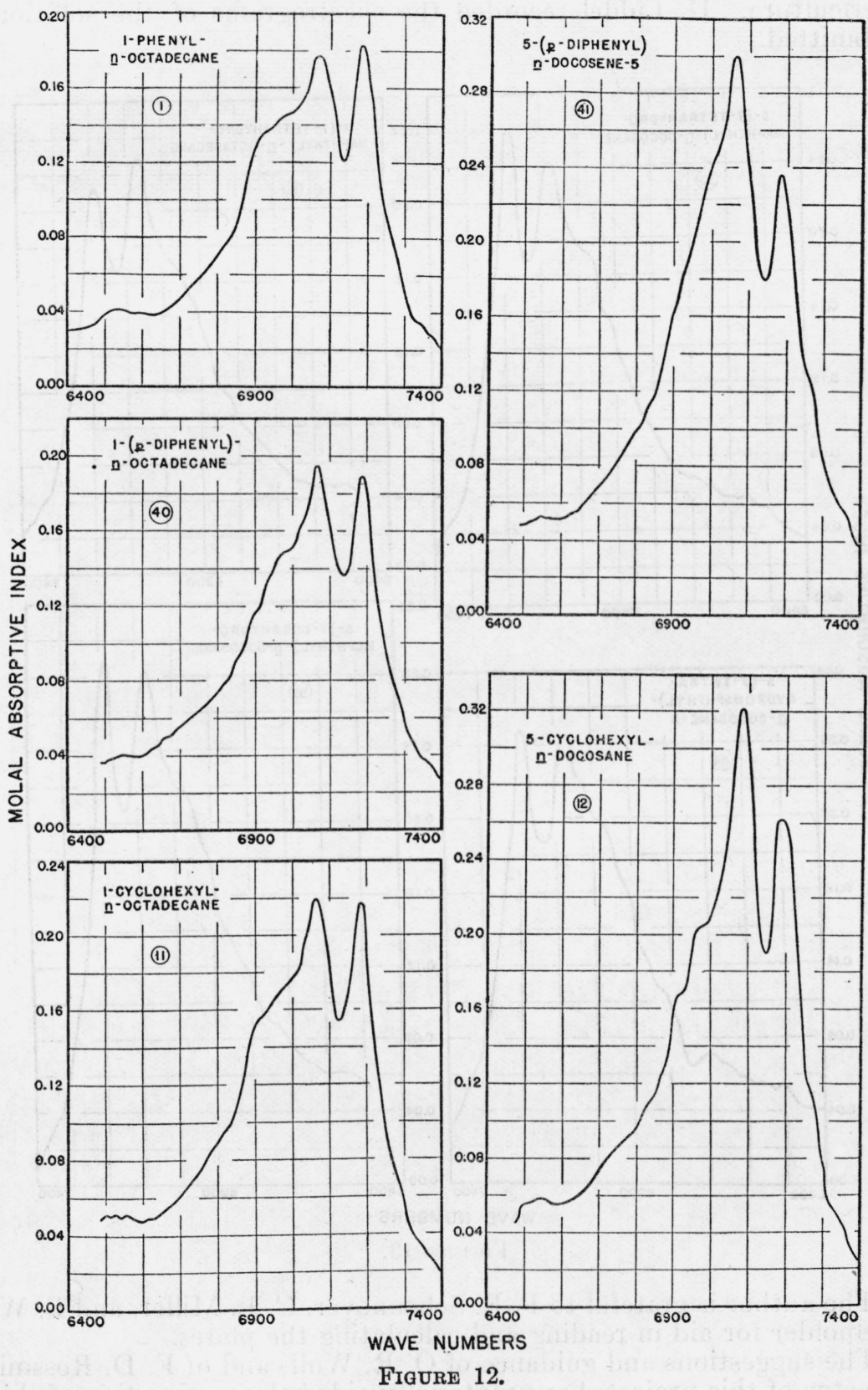


This work was made possible by the courtesy and cooperation of O. R. Wulf, of the Bureau of Chemistry and Soils, Department of Agriculture. U. Liddel recorded the spectrograms of the solutions submitted.

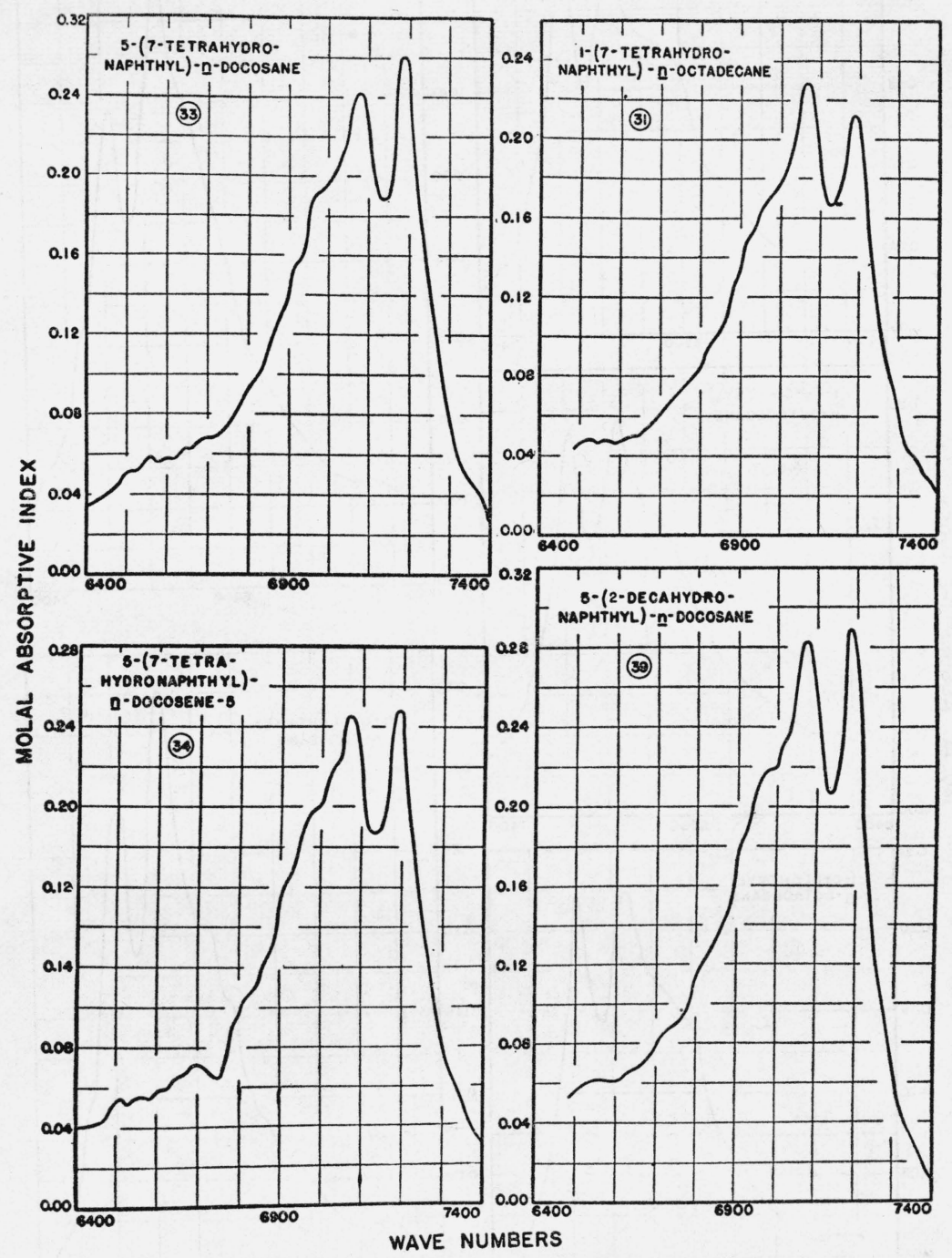

FIGURE 13.

The author is grateful to P. E. Schoonover, C. L. Miller, and F. W. Melpolder for aid in reading and calculating the plates.

The suggestions and guidance of O. R. Wulf, and of F. D. Rossini, director of this project, have materially aided the preparation of this report. 


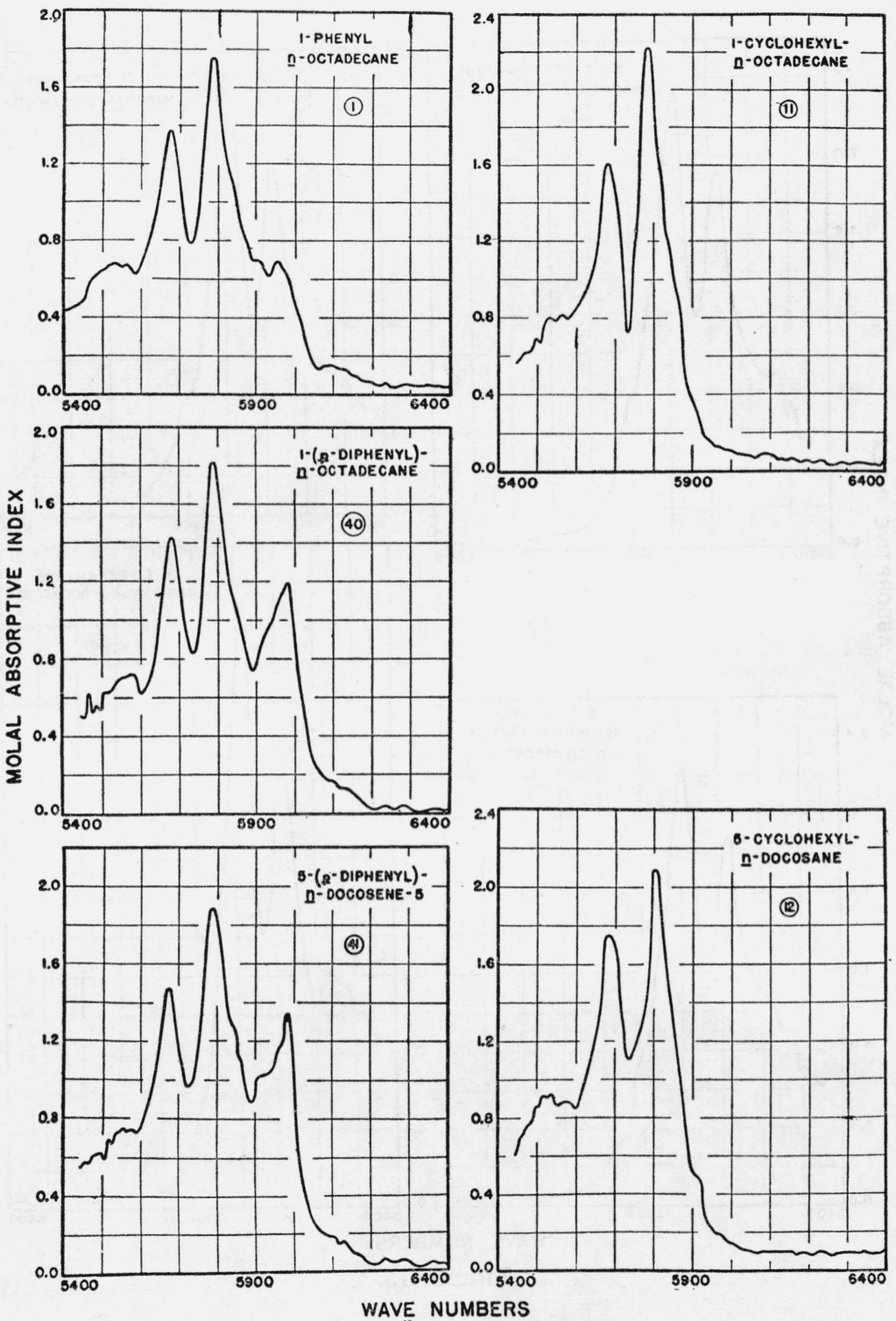

Figure 14. 


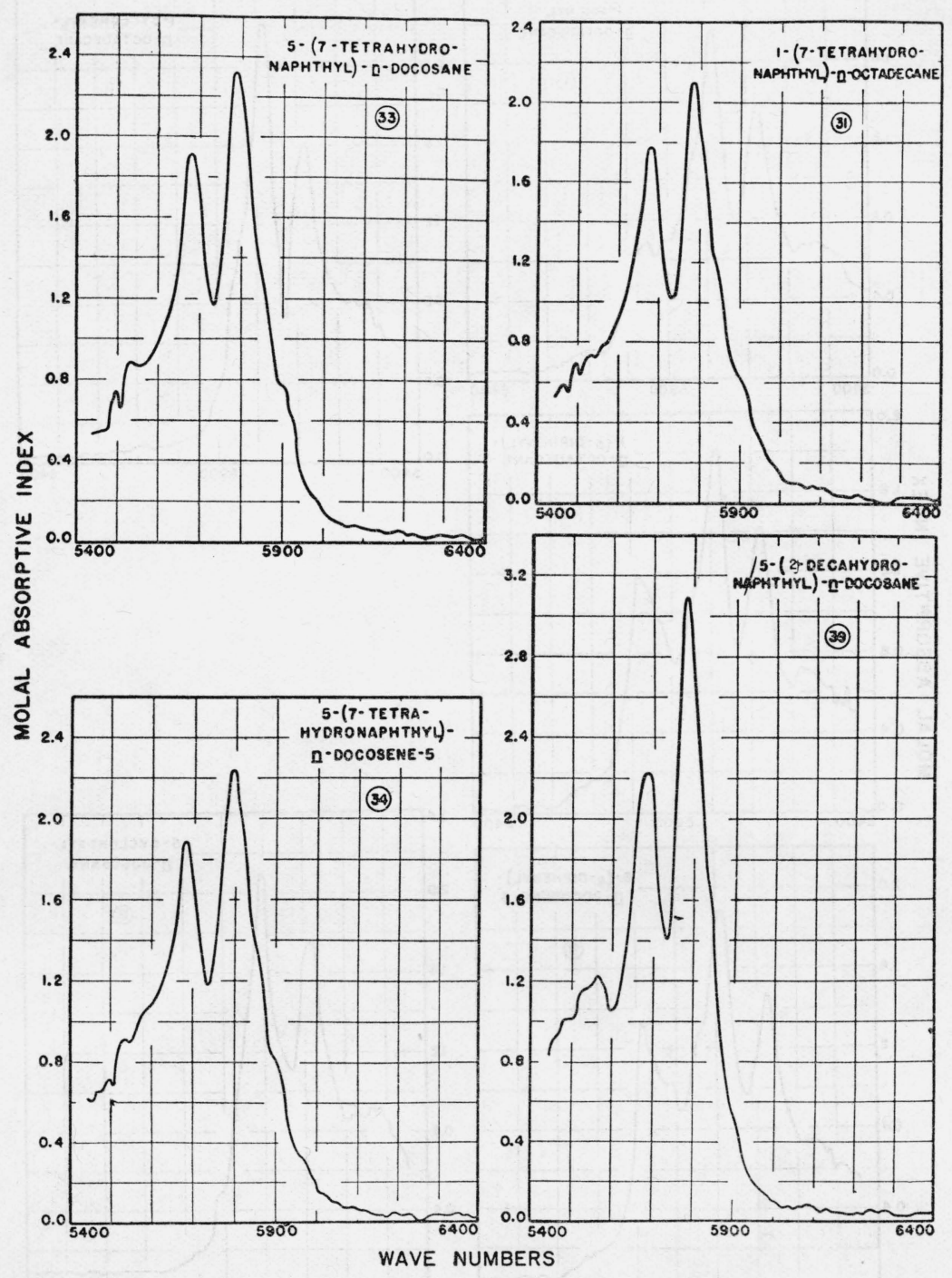

FigURE 15. 


\section{REFERENCES}

[1] U. Liddel and C. Kasper. BS J. Research 10, 599-618 (1933) RP610.

[2] F. S. Brackett and U. Liddel. Smithsonian Misc. Coll. 85, no. 5 (1931).

[3] U. Liddel and O. R. Wulf. J. Am. Chem. Soc. 55, 3574 (1933).

[4] O. R. Wulf and U. Liddel, J. Am. Chem. Soc. 57, 1464 (1935).

[5] G. Calingaert and H. Soroos. J. Am. Chem. Soc. 58, 635 (1936).

[6] N. L. Drake and L. H. Welsh, University of Maryland; forthcoming publication.

[7] W. B. Holton and students, American University; report as yet unpublished.

[8] E. E. Reid and students, The Johns Hopkins University, report as yet unpublished.

[9] F. W. Rose, Jr., and J. D. White. J. Research NBS 15, 151 (1935) RP817.

[10] L. A. Mikeska, Ind. Eng. Chem. 28, 970 (1936).

[11] K. S. Markley, S. B. Hendricks, and C. E. Sando, J. Biol. Chem. 98, 103 (1932).

[12] K. S. Markley and C. E. Sando. J. Biol. Chem. 101, 431 (1933).

[13] B. J. Mair and S. T. Schicktanz. Ind. Eng. Chem. 28, 1448 (1936).

[14] O. R. Wulf, U. Liddel, and S. B. Hendricks. J. Am. Chem. Soc. 58, 2287 (1936).

[15] F. S. Brackett. Proc. Nat. Acad. Sci. 14, 857-864 (1928).

[16] J. Lecomte. Structure des Molécules et Spectres dans l'Infra-Rouge. (Masson et Cie., Paris, 1936).

[17] J. D. White and F. W. Rose, Jr., J. Research NBS; forthcoming publication.

Washington, June 15, 1937. 